\title{
Tissue Specific and Variable Collagen Proliferation in Swiss Albino Mice Treated with Clenbuterol
}

\author{
S. N. PATIYAL, S. S. KATOCH \\ Department of Biosciences, Himachal Pradesh University, Summer Hill, Shimla, India \\ Received August 6, 2004 \\ Accepted March 1, 2005 \\ On-line available April 26, 2005
}

\begin{abstract}
Summary
Chronic administration of clenbuterol, a beta-adrenoceptor agonist ( $2 \mathrm{mg} / \mathrm{kg}$ body weight/day for 30 days) to mice resulted in an increased body mass. Measurement of dry tissue mass suggested a protein anabolic effect in the gastrocnemius and heart. Quantitative estimation of collagen content, a non-contractile element as calculated from hydroxyproline assay revealed its proliferation in the gastrocnemius, cardiac ventricle, intestine and to some extent also in the kidney. Clenbuterol did not induce collagen proliferation in non-muscle tissues such as the lungs and liver. Histopathological examination of sections from treated ventricles showed an extensive collagen infiltration in the subendocardium and at myonecrosis sites.
\end{abstract}

Key words

Clenbuterol $\bullet$ Hydroxyproline $\bullet$ Collagen $\bullet$ Endocardium

\section{Introduction}

Beta-adrenoceptor agonists like clenbuterol, cimaterol and isoproterenol are known to produce specific protein anabolic effects in skeletal muscle in addition to lipolysis in the adipose tissue of different vertebrates (Baker et al. 1984, Choo et al. 1992, Kim and Sainz 1992, Moore et al. 1994, Kumar et al. 2003, Agrawal et al. 2003). The drugs are therefore employed in repartitioning and production of lean meat in commercial poultry and other animals (Elliott et al. 1993). By virtue of their ability to enhance protein biosynthesis (Maltin et al. 1992, Hesketh et al. 1992), $\beta$ adrenoceptor agonists are commonly used by athletes especially those involved in strength and power performance related games (Delbecke et al. 1995). The drugs are, however, banned for common use. Clenbuterol, one of the most widely tested $\beta$-adrenoceptor drug, has been used in concentrations ranging from $1-5 \mathrm{mg} / \mathrm{kg}$ body weight in different vertebrates. In response to such doses the size of heart, skeletal muscle, bone, lung and kidney all increase whereas tissues like liver and adipose show a decrease in mass (Von Deutsch et al. 2000). Protein anabolic effects of different $\beta$-adrenoceptor agonists are not only restricted to normal innervated skeletal muscles but have been equally documented in conditions characterized by atrophy of the constituent muscle cells. Thus different beta agonists including clenbuterol can oppose muscle weaknesses in aged muscles (Carter et al. 1991) or conditions arising in a variety of neuromuscular disorders like denervation atrophy (Zeman et al. 1987, Agrawal et al. 2003). The drugs can even reverse dystrophic states (Dupont-Versteegden et al. 1995). Owing to its bronchodilatory properties, clenbuterol is also used therapeutically to relieve respiratory disorders in humans and animals (Boyd et al. 1994). Although $\beta$ - 
adrenoceptor agonists have potent specific protein anabolic effects in skeletal muscle, yet a chronic use of these substances produces a deleterious effect on vital organs like the heart. An overall hypertrophy of heart in different animals in response to $\beta$-agonist treatments is well known. Hearts of sedentary rats treated with clenbuterol exhibited an infiltration of ventricular tissue with collagen (Duncan et al. 2000) and thereby potentially produces changes in muscle structure and functions, such as myocardial fibrosis. Collagen is a noncontractile protein of the extracellular matrix that controls the functional organization of the tissue and thereby modulates myocardial compliance (Eghbali et al. 1988) and hence cardiac output.

Clenbuterol may even induce cell death and necrosis in the heart and higher doses of drug $(5 \mathrm{mg} / \mathrm{kg}$ body weight) produce myotoxic effects in the heart and soleus muscle of rats (Burniston et al. 2002). The utility of chronic use of $\beta$-adrenoceptor agonists in producing an accelerated protein accretion in skeletal muscle is, however, bellied by simultaneous and deleterious effects on the heart. The aim of this study was to evaluate, in both qualitative and quantitative terms, the collagen proliferation in ventricular tissue of Swiss albino mice by employing hydroxyproline assay. More specifically we were interested to confirm tissue-specific collagen proliferation by including other non-muscle tissues as well.

\section{Methods}

Eight weeks old and sexually mature adult male white Swiss albino mice, weighing approximately $22 \pm 3 \mathrm{~g}$, were procured from the Central Research Institute, Kasauli, Himachal Pradesh, India. The mice were housed in flat bottomed polypropylene cages and maintained in the animal house of the Department of Biosciences of Himachal Pradesh University under appropriate conditions as approved by Institutional Animals Ethics Committee, providing $16 \mathrm{~h}$ daylight and a temperature of $24 \pm 2{ }^{\circ} \mathrm{C}$. Animals were provided food and water ad libitum. A total of 40 mice were divided into three groups:

(a) Mice $(n=15)$ in the first group were given a daily oral administration of clenbuterol $(2 \mathrm{mg} / \mathrm{kg}$ body weight) for 30 days. Five mice were killed on the last day of drug administration for (i) quantitative assay and (ii) qualitative distribution of collagen in left ventricle respectively. Remaining 5 mice were maintained further till day 45 but without any drug treatment. This was specifically aimed at ascertaining the effect of drug withdrawal on the collagen content, which was finally determined in these animals on day 45 .

(b) Mice $(n=10)$ in the second group received clenbuterol as in group (a) and also a $\beta$-adrenoceptor antagonist butoxamine (2 $\mathrm{mg} / \mathrm{kg}$ body weight) simultaneously for 30 days. While 5 mice were killed on day 30 for the quantitative assay of collagen, remaining 5 mice were maintained till day 45 . This group did not receive either of the two drugs. Collagen content was assayed in these mice on day 45 .

(c) The third group comprised of age-matched control mice $(n=15)$. Out of this, 5 mice each were employed for quantitative assay of collagen on day 30 and 45. Five mice were killed separately on day 30 and used for studying qualitative distribution of collagen in left ventricle by van Gieson staining.

A complete record of the body weight and heart weight of mice used in quantitative assays was maintained. Cardiac hypertrophy was confirmed by measuring dry tissue mass using a procedure described by Agrawal et al. (2003).

\section{Administration of drugs}

Each mouse in the group (a) and/or (b) was daily given an oral dose of clenbuterol and butoxamine $2 \mathrm{mg} / \mathrm{kg}$ body weight for 30 days. Stock solutions of clenbuterol $(10 \mathrm{mg} / \mathrm{ml})$ and butoxamine $(5 \mathrm{mg} / \mathrm{ml})$ were prepared in sterilized distilled water. Further dilutions from stock solutions were performed according to weight records at the time of the experiment.

\section{Histopathological study}

Van Gieson stain (1 part $1 \%$ aqueous acid fuchsin, 9 parts saturated picric acid and 10 parts distilled water) was employed to identify proliferation of noncontractile/collagen distribution in Bouin's fixed $6 \mu \mathrm{m}$ thick tissue sections from the left ventricle only.

\section{Hydroxyproline assay}

Total collagen content in different tissues was calculated following the hydroxyproline assay as described by Bergman and Loxley (1963) with slight modifications. For heart tissue, posterior one third of left ventricle was employed in quantitative estimation of hydroxyproline. Weighed amounts of fine slices of different tissues $(100 \mathrm{mg})$ were digested in $5 \mathrm{M} \mathrm{HCl}$ at $100{ }^{\circ} \mathrm{C}$ for $4 \mathrm{~h}$. Tissue homogenates were then decolori- 
zed with activated charcoal. These were gravity filtered after 2 min and rinsed with $800 \mu \mathrm{M} \mathrm{NaOH}$ and $500 \mu \mathrm{l}$ of distilled water.

$200 \mu \mathrm{l}$ of clear extract/supernatant was oxidized with chloramine $\mathrm{T}$ solution for $20 \mathrm{~min}$ at room temperature. The mixture was then heated with $\mathrm{p}$ dimethylaminobenzaldehyde at $60{ }^{\circ} \mathrm{C}$ for $20 \mathrm{~min}$. Full color development reached in $15 \mathrm{~min}$. Samples were cold centrifuged at $3500 \mathrm{x} \mathrm{g}$ for $10 \mathrm{~min}$. Absorbance was read at $550 \mathrm{~nm}$ in Hitachi 150-20 double-beam spectrophotometer.

A standard calibration curve was plotted for 4-hydroxyproline (SRL Pvt. Bombay) and regression line drawn. A conversion factor of 7.14 was employed to convert hydroxyproline into collagen (calculated from standard curve) assuming that collagen contains $14 \%$ 4- hydroxyproline (Brilla et al. 1994). Collagen content was finally expressed in $\mu \mathrm{g} / \mathrm{mg}$ fresh tissue weight. Clenbuterol and butoxamine were purchased from Sigma Chemical Co. USA. Other routine chemicals were obtained from local suppliers.

\section{Statistical analysis}

Data have been expressed as mean \pm SEM. Statistical significance was determined by Student's t-test to find the differences between group means. Differences were assumed to be significant at $\mathrm{p}<0.05$.

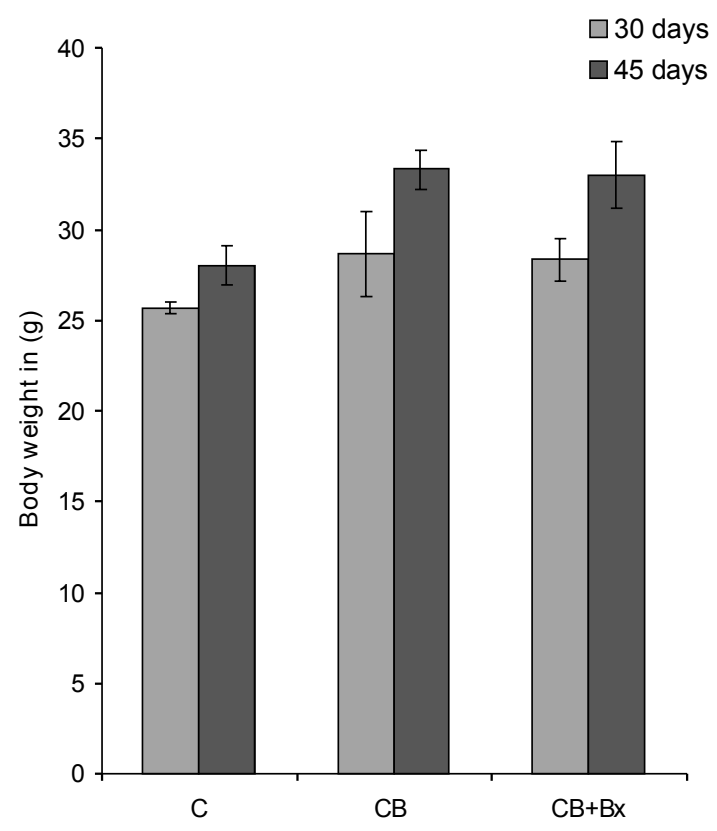

Fig. 1. Changes in body weight of mice treated with clenbuterol ( $2 \mathrm{mg} / \mathrm{kg}$ body weight/day; duration of treatment 30 days). The effects of drug continued even when drug administration had been withdrawn (at 45 days). Values are \pm SEM; $n=5$ each. $C=$ Control; $\mathrm{CB}=$ Clenbuterol-treated; $\mathrm{CB}+\mathrm{Bx}=$ Clenbuterol and butoxamine-treated.

\section{Results}

Chronic administration of clenbuterol to mice for 30 days resulted in more than $11 \%$ increase in body weight (Fig. 1). Treated animals exhibited a mean body weight of $28.66 \pm 2.33 \mathrm{~g} ; \mathrm{n}=5$ compared to mean body weight of $25.66 \pm 0.33 \mathrm{~g}$ in age matched control mice on day 30. Butoxamine administration to clenbuterol-treated group did not influence the augmented body growth and the animals in this group continued to maintain body weight equivalent to that of the treated group $(28.33 \pm 1.20$ $\mathrm{g} ; \mathrm{n}=5$ ). Butoxamine was again only partially effective in reversing $\beta$-adrenoceptor agonist-induced cardiac hypertrophy in mice, although daily administration of clenbuterol for 30 days caused an increase of more than $14 \%$ in heart muscle mass (control hearts $129.66 \pm 1.20 \mathrm{mg}$, clenbuterol-treated $148.33 \pm 12.80$ and clenbuterol + butoxamine $141.00 \pm 4.58 \mathrm{mg}$; $\mathrm{n}=5$ each) (Fig. 2). Parallel increments in body weight and heart muscle mass demonstrated a muscle specific protein anabolic effect of clenbuterol. This is because more than two thirds of body mass in all vertebrates is composed of muscle tissue and hence tissue contribution to body mass is considerable. An enormous cardiac hypertrophy, however, remained established even on day 45, i.e. 15 days following drug withdrawal (heart weight 176.66 $\pm 2.40 \mathrm{mg} ; \mathrm{n}=5$ ) (Fig. 2).

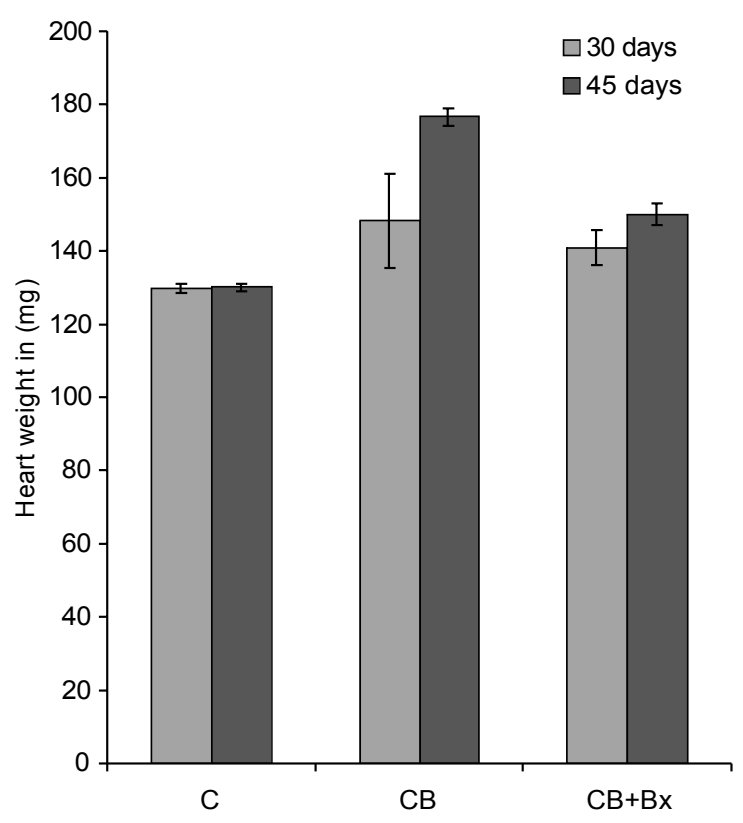

Fig. 2. Administration of clenbuterol, a beta-adrenoceptor agonist results in cardiac hypertrophy as revealed by changes in organ weight. Hypertrophying effects on heart were more significant on day 45 (15 days following the withdrawal of drug administration). Values are \pm SEM; $n=5$ each. $C=$ Control; $C B=$ Clenbuteroltreated; $\mathrm{CB}+\mathrm{Bx}=$ Clenbuterol and butoxamine-treated. 


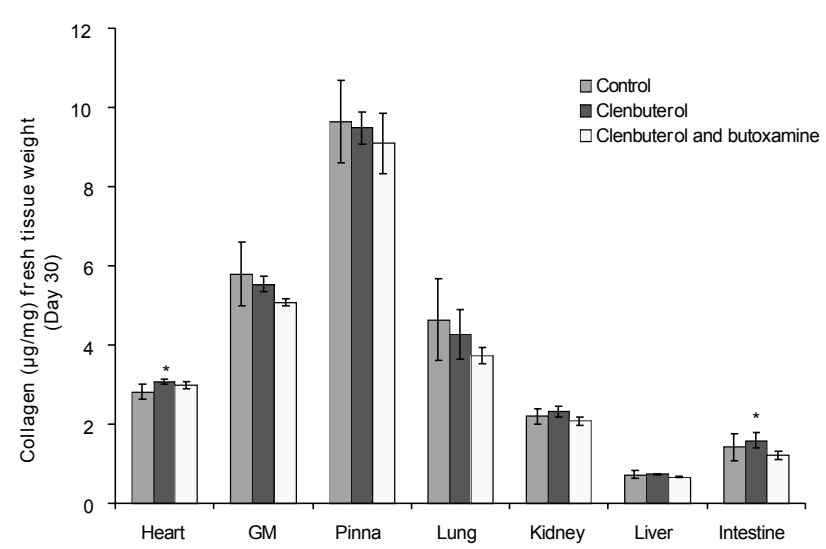

Fig. 3. Collagen concentration in different tissues of mice treated with clenbuterol. Values are \pm S.E.M. $(n=5$ each; $* p<0.05)$. $\mathrm{GM}=$ gastrocnemius muscle.

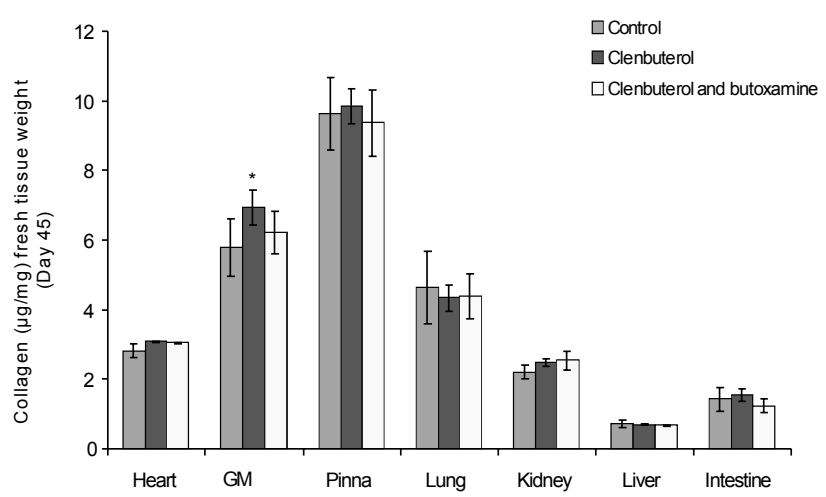

Fig. 4. Clenbuterol-induced changes in the collagen content of gastrocnemius muscle (GM), heart, intestine and kidney on day 45 ( 15 days after the drug administration was withdrawn). Values are \pm S.E.M. $(n=5$ each; $* p<0.05)$.
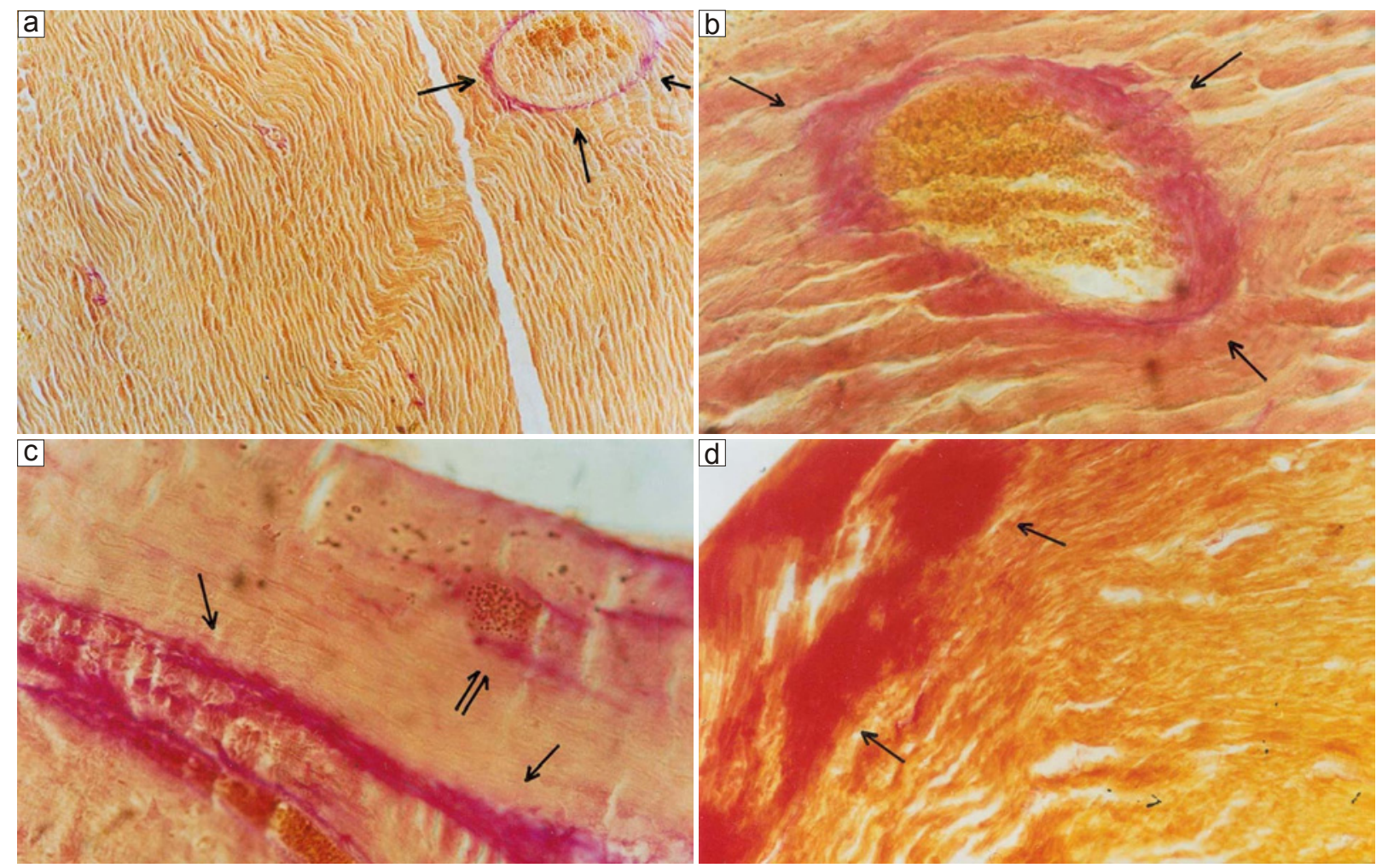

Fig. 5. (a) Longitudinal section of ventricle from control mice stained with van Gieson stain showing a scarce distribution of collagen in the tissue. Thin strip of collagen is restricted to blood vessels only (arrows). (b) Ventricular section from clenbuterol-treated mice stained with van Gieson stain showing an extensive proliferation of collagen around blood vessels (arrows). (c) Longitudinal section of mice ventricle treated with clenbuterol and stained with van Gieson stain showing muscle fiber undergoing myonecrosis. There is heavy accumulation of collagen along the sarcolemma (single arrow) and in myonecrotic regions (double arrow). (d) Longitudinal section of mice ventricle treated with clenbuterol and stained with van Gieson stain. Thick collagen patches covering affected cardiac fibers are very commonly observed (arrows). Focal areas showing large myonecrosis are common.

Gastrocnemius muscle from normal innervated mice demonstrated a collagen content of $5.79 \pm 0.82(\mathrm{n}=5)$ $\mu \mathrm{g} / \mathrm{mg}$ fresh tissue weight which was more than two times higher than that of ventricular tissue $(2.82 \pm 0.18$ $\mu \mathrm{g} / \mathrm{mg}$ fresh tissue weight; $\mathrm{n}=5$ ) (Fig. 3). Administration of clenbuterol interestingly induced a different response in these two muscles. Beta-agonist-induced increase of collagen content, although significant $(>19 \%$; $<<0.05)$, was delayed in gastrocnemius muscle and was confirmed only on day 45 , i.e. 15 days after drug administration had been stopped (Fig. 4). On day 30, an insignificant decline in the collagen content as compared to normal controls 
was noticed in this muscle. Heart ventricle, on the other hand, demonstrated increased collagen content on the day 30 , which was not affected by butoxamine on day 30 and beyond. Collagen contents of different non-muscle tissues as calculated from hydroxyproline assay revealed that pinna exhibited predictably highest content $(9.64 \pm 1.04$ $\mu \mathrm{g} / \mathrm{mg} ; \mathrm{n}=5$ animals). Lungs $(4.64 \pm 0.67 \mu \mathrm{g} / \mathrm{mg} ; \mathrm{n}=5)$, kidney $(2.20 \pm 0.19 \mu \mathrm{g} / \mathrm{mg} ; \mathrm{n}=5)$, intestine $(1.42 \pm 0.34$ $\mu \mathrm{g} / \mathrm{mg} ; \mathrm{n}=5)$ and liver $(0.725 \pm 0.11 \mu \mathrm{g} / \mathrm{mg} ; \mathrm{n}=5)$ followed in decreasing magnitude of concentration. Interestingly clenbuterol treatment resulted in a collagen increase in intestine on day $30(>11 \% ; \mathrm{p}<0.05)$ and kidney $(>5 \%$; not significant) without much influencing the noncontractile element of pinna, lung, and liver. Respective increments in collagen could be confirmed by employing $\beta$-adrenoceptor antagonist, butoxamine. The increments were long-lasting since these could continue even beyond day 30 when the drug administration had already been withdrawn. Amount of collagen in pinna, lungs, liver almost fluctuated around levels characteristic for control levels implying the $\beta$-adrenoceptor agonists are largely ineffective in non-muscle tissues. Van Gieson staining employed to determine qualitative changes in noncontractile element demonstrated collagen increase especially around blood capillaries and in those regions in ventricular myocardium, which showed myonecrosis. Collagen is mainly distributed in extremely low quantities along adventitia of the blood vessels and in perimysial layers of subendocardium from control animals (Fig. 5a). Ventricular myocardium in general is either devoid of any collagen or exhibits an association with negligible non-contractile element. Interestingly, clenbuterol, treatment results in an extensive infiltration of myocardium with collagen especially around blood capillaries (Fig. 5b) and myonecrotic regions (Fig. 5c). Collagen infiltration is evident in the form of pink and dark brown stained areas prevalent in perimysial regions and the blood vessels. Many cell-free areas adjacent to high-infiltered collagen are commonly observed (Fig. 5d).

\section{Discussion}

We have demonstrated that chronic administration of clenbuterol to normal mice results in an increased body mass following accelerated skeletal muscle growth including cardiac muscle hypertrophy. The anabolic effect of clenbuterol is accompanied by a considerable collagen infiltration in the ventricular subendocardium. The growth stimulating effect of the $\beta$-adrenoceptor agonist also extends to non-muscle tissues like kidney and intestine. Both in terms of its anabolic influences and physiological effects, clenbuterol was found to be ineffective in other non-muscle tissues. The muscle specific anabolic effects of $\beta$-adrenoceptor agonists have been widely documented in different sedentary and livestock vertebrates (Choo et al. 1992, Rehfeldt et al. 1997, Kumar et al. 2003, Agrawal et al. 2003). The mass of skeletal muscle, heart, lung, kidney and bone increased in response to doses ranging from 2-5 $\mathrm{mg} / \mathrm{kg}$ body weight. It has yet to be proven, however, that $\beta$-adrenoceptor agonist induced skeletal muscle and cardiac hypertrophy as a result of an increased nitrogen retention is of any functional significance. There is already concern that the administration of these drugs may be antagonistic to muscular and cardiovascular adaptation to exercise (Burniston et al. 2002). Clenbuterol resulted in a more than $14 \%$ cardiac hypertrophy which persisted even beyond the period when drug had been withdrawn implying that beta agonist effects on cardiac muscle are long-lasting. Butoxamine at a concentration of $2 \mathrm{mg} / \mathrm{kg}$ body weight failed to inhibit hypertrophic effect of clenbuterol. Either the concentration employed were too low to inhibit clenbuterol effects or clenbuterol acts by a mechanism other than simple activation of $\beta_{2}$-adrenoceptors. Clenbuterol is lipophilic in nature and is likely to produce direct intracellular actions (Bakker et al. 1996). Although clenbuterol is a $\beta_{2}$-adrenoceptor agonist, there are reports suggesting that the drug may be acting via activation of $\beta_{3}$-adrenoceptors.

One of the important observations in the current study included a significant (more than $9 \%$; $<<0.05$ ) increase in collagen content of ventricular myocardium raising further questions about the clinical utility of longterm beta-agonist therapy in rehabilitation or reconstruction of wasting and other related disorders. Collagen is a non-contractile protein which plays an important role in regulating myocardial contractility and hence it is instrumental in controlling many hemodynamic functions. Results more than convincingly demonstrate accumulation of collagen around blood vessels and other necrotic regions. Control myocardium exhibited connective tissue/collagen in extremely small amounts and wherever present it is rather restricted to adventitia of blood vessels or to perimysial rings only. The muscle sections from drug-treated ventricular myocardium revealed conspicuously thickened collagen 
bands surrounding different blood vessels. Localized areas in the rest of myocardium especially in subendocardium showed excessive accumulation of collagen as revealed by van Gieson staining. The finding that there is an extensive myonecrosis accompanied by collagen proliferation in endocardium demonstrates that before beta-agonists like clenbuterol can be employed in any rehabilitation programs or for the purpose of enhancing strength performances, the potential myotoxic effects of such drugs need to be evaluated in details. Utility of these substances especially when these are applied for longer time have potentially more threats to vital organs like heart and other highly vascularized tissues like kidney and intestine. The beta-agonist-induced increased collagen accumulation can lead to a pathophysiological state characterized by reduced coronary blood flow, reduced hyperemic flow following alterations in ventricular compliance. Collagen content and distribution certainly affects ventricular compliance. Petrou et al. (1995) documented an 18-20\% cardiac hypertrophy after clenbuterol treatment that was shown at molecular level to be a physiological one. Duncan et al. (2000) reported as much as $19 \%$ cardiac hypertrophy due to clenbuterol treatment with an extensive collagen infiltration surrounding blood vessels and in the ventricular walls.

\section{Acknowledgements}

Thanks are due to Council of Scientific and Industrial Research (CSIR) New Delhi for the award of Junior Research Fellowship to SNP.

\section{References}

AGRAWAL S, THAKUR P, KATOCH SS: Beta adrenoceptor agonists, clenbuterol and isoproterenol retard denervation atrophy in rat gastrocnemius muscle: use of 3-methylhistidine as a marker of myofibrillar degeneration. Jpn J Physiol 53: 229-237, 2003.

BAKER PK, DALRYMPLE RH, INGLE DL, RICKS CA: Use of a $\beta_{2}$-adrenergic agonist to alter muscle and fat deposition in lambs. J Anim Sci 59: 1256-1261, 1984.

BAKKER AJ, HEAD SI, WAREHAM AC, STEPHENSON DG: Effect of clenbuterol on sarcoplasmic reticulum function in single skinned mammalian skeletal muscle fibers. Am J Physiol 274: C1718-C1726, 1996.

BERGMAN I, LOXLEY R: Two improved and simplified methods for the spectrophotometric determination of hydroxyproline. Anal Chem 35: 1961-1965, 1963.

BRILLA CG, ZHAU G, MATSUBARA L, WEBER KT: Collagen metabolism in cultured adult rat cardiac fibroblasts: response to angiotensin II and aldosterone. J Mol Cell Cardiol 26: 809-820, 1994.

BOYD D, 'O' KEEFE M, SMY MR: Matrix solid phase dispersion as a multiresidue extraction technique for $\beta_{2^{-}}$ agonists in the bovine liver tissue. Analyst 19: 1467-1470, 1994.

BURNISTON JG, YEELEN NG, CLARK WA, COLYER J, TAN LB, GOLDSPINK DF: Myotoxic effects of clenbuterol in the rat heart and soleus muscle. J Appl Physiol 93: 1824-1832, 2002.

CARTER W, DANG A, FOSS F, LYNCH M: Effect of clenbuterol on muscle mass, body composition and recovery from surgical stress in senescent rats. Metabolism 40: 855-860, 1991.

CHOO JJ, HORAN MA, LITTLE RA, ROTHWELL NJ: Anabolic effects of clenbuterol on skeletal muscle are mediated by $\beta_{2}$-adrenoceptor activation. Am J Physiol 262: E50-E56, 1992.

DELBECKE FT, DESMET N, DEBACKERE M: The abuse of doping agent in competing body builders in Flanders (1988-1993). Int J Sports Med 16: 66-70, 1995.

DUNCAN ND, WILLIAMS DA, LYNCH GS: Deleterious effects of chronic clenbuterol treatment on endurance and sprint exercise performance in rats. Clin Sci 98: 339-347, 2000.

DUPONT-VERSTEEGDEN EE, KATZ MS, MCCARTER RJ: Beneficial versus adverse effects of long-term use of clenbuterol in mdx rats. Muscle Nerve 18: 1447-1459, 1995.

EGHBALI M, CZAJA MJ, ZEYDEL M, WEINER FR, ZERN MA, SEIFTER F, BLUMENFELD OO: Collagen chain mRNAs in isolated heart cells from young and adult rats. J Mol Cell Cardiol 20: 267-276, 1988.

ELLIOTT CT, CROOKS SR, MCEVOY JG, MCCAUGHEY WJ, HEWITT SA, PATTERSON D, KILPATRICK D: Observations on the effects of long-term withdrawal on carcass composition and residue concentrations in clenbuterol-medicated cattle. Vet Res Commun 17: 459-468, 1993. 
HESKETH JE, CAMPBELL GP, LOBLEY GE, MALTIN CA, ACAMOVIC F, PALMER RM: Stimulation of actin and myosin synthesis in rat gastrocnemius muscle by clenbuterol: evidence for a translational control. Comp Biochem Physiol C 102: 23-27, 1992.

KIM YS, SAINZ RD: $\beta_{2}$-adrenergic agonist and hypertrophy of skeletal muscles. Life Sci 50: 397-407, 1992.

KUMAR S, SHARMA S, KATOCH SS: Early onset of the maximum protein anabolic effect induced by isoproterenol in chick skeletal and cardiac muscle. Acta Physiol Hung 90: 57-67, 2003.

MALTIN CA, HAYS SM, MCMILLAN DN, DELDAY MI: Tissue specific responses to clenbuterol: temporal changes in protein metabolism in striated and visceral tissues. Growth Reg 2: 161-167, 1992.

MOORE NG, PEGG GC, SILLENCE MN: Anabolic effects of the $\beta_{2}$-adrenoceptor agonist salmaterol are dependent upon route of administration. Am J Physiol 267: E475-E484, 1994.

PETROU M, WYNNE DG, BOEHLER KR, YACOUB MH: Clenbuterol induced hypertrophy of the latissimus dorsi muscle and heart in the rat with molecular and phenotypic changes. Circulation 92: 483-489, 1995.

REHFELDT C, SCHARDERLET R, WEIKARD R, REICHEL K: Effect of clenbuterol on growth, carcass and skeletal muscle characteristics in broiler chickens. Br Poultry Sci 38: 366-373, 1997.

VON DEUTSCH DA, ABUKHALF IA, WINESKI LE, ABOUL-ENSEIN HY, PITTS SA, PARKS BA, OSTER RA, PAULSEN DF, EPD: Beta-agonist induced alterations in organ weights and protein content: comparison of racemic clenbuterol and its enantiomers. Chirality 12: 637-648, 2000.

ZEMAN RJ, LUDEMANN R, ETLINGER JD: Clenbuterol, a $\beta_{2}$-agonist retards atrophy in denervated muscles. Am $J$ Physiol 252: E152-E155, 1987.

\section{Reprint requests}

Som N. Patiyal, Senior Research Fellow, Dept. of Biosciences, Himachal Pradesh University, Shimla-171005, India.

E-mail: snpatiyal@yahoo.co.in 